\title{
Integrative Ethical Education: An Exploratory Investigation Into a Relationally Based Approach to Ethics Education
}

\author{
Drew T. Ashby-King \\ Karen D. Boyd
}

Keywords: communication education, instructional communication, ethics education, pedagogy, student development

\begin{abstract}
The purpose of this exploratory study was to investigate the effect of a curricular application of the integrative ethical education (IEE) model (Narvaez, 2006; Narvaez \& Bock, 2014) and its effect on first-year college students' ethical development. Using a pretest posttest design, participants' moral judgment and reasoning were measured before and after they participated in an IEE-based academic course and compared using descriptive analysis. Results revealed that participants' moral judgment and reasoning increased while participating in the program. These results provide initial support for the use of IEE-based curricula and academic experiences to promote college students' ethical development. Implications for communication education and future research are discussed.
\end{abstract}

Moral and ethical development have been identified as desired college student learning outcomes both broadly (American Council on Education, 1937; Association of American Colleges and Universities, 2005, 2007) and within the communication discipline (National Communication Association [NCA], 2015). Broadly, researchers have determined that ethical growth is an essential outcome to equip students to participate in democratic society (Colby et al., 2003; O'Neill, 2011). More specifically, the

Drew T. Ashby-King, University of Maryland

Karen D. Boyd, University of Tennessee, Knoxville, TN

CONTACT: dashbyk@umd.edu

Author's note: This study was funded by a grant from NASPA: Student Affairs Administrators in Higher Education-Region III. A previous draft of this paper was presented at the 2019 annual meeting of the National Communication Association. This work developed from the first author's master's thesis and the authors would like to thank Norma T. Mertz and J. Patrick Biddix for their feedback throughout this project. 
NCA (2015) outlined the ability to "apply ethical communication principles and practices" (p. 7) as a key learning outcome for students majoring in communication. In other words, students should be able to identify a variety of ethical perspectives and explain the relevance of each, evaluate the ethical aspects of a communication situation, offer solutions in situations that may lead to unethical communication, and demonstrate a conscious intent to communicate ethically. To achieve this learning outcome, the communication curriculum should include ethics education that promotes the development of moral judgment and reasoning (Canary, 2007).

Limited research has focused on classroom interventions to enhance students' ethical development (Mayhew, Rockenbach, et al., 2016) despite numerous studies making connections between academic experiences and ethical development (Mayhew \& King, 2008; Mayhew, Seifert, Pascarella et al., 2012). Although these studies do offer important insight, they fail to provide specific pedagogical practices and communication behaviors that may influence students' ethical development. Learning how various pedagogical strategies influence students' ethical development may empower instructors to employ them intentionally to increase students' ethical development.

This exploratory study investigates first-year college students' ethical development when participating in two academic courses designed in ways that employ the integrative ethical education (IEE) model (Narvaez, 2006; Narvaez \& Bock, 2014). Narvaez's IEE model focuses on creating educational environments that promote students' ethical growth. The first-year experience program investigated in this study-part of an interdisciplinary honors leadership program-is a two-semester sequence where students also live in an on-campus living-learning community and participate in cocurricular leadership activities.

\section{Moral and Ethical Development in College}

Some research suggests that participating in postsecondary education may positively influence an individual's moral and ethical development (e.g., Corcoran \& O'Flaherty, 2016; Maeda et al., 2009; Mayhew, Rockenbach, et al., 2016). Moreover, it appears that the largest gains occur during the first year (King \& Mayhew, 2002; Pascarella, Blaich, et al., 2011). Moral and ethical development are active processes that occur when students engage with their peers and instructors. For example, high-quality teaching, interacting with peers, being challenged by instructors who asked thought-provoking questions, and applying course concepts to real-world experiences have had positive effects on college students' moral and ethical development (Mayhew, Seifert, \& Pascarella, 2010).

Scholars have also investigated moral and ethical development throughout the college experience. For example, ethics courses (Aalberts et al., 2012; Auger \& Gee, 2016; Mayhew \& King, 2008; Walling, 2015), service learning (Lies et al., 2012), deep learning (Mayhew, Seifert, Pascarella, et al., 2012), and diversity courses (Hurtado et al., 2012; Mayhew \& Engberg, 2010; Mayhew, Seifert, \& Pascarella, 2012; Parker et al., 2016), have been examined as they may positively influence students' moral and ethical development.

Some research suggests that applying a model of ethical education in a college class may increase students' awareness of multiple perspectives (Aalberts et al., 2012). More specifically, Walling (2015), for instance, discovered that active learning in a discipline-specific ethics course helped students develop new identities as moral agents and understand ethical decision-making as a practice. Similarly, Lies et al. (2012) observed that service learning tended to increase students' moral reasoning development. Moreover, they discovered that the largest increases occurred when overt moral content was included 
in the course. Mayhew, Seifert, Pascarella, et al. (2012) found a significant positive relationship between deep learning practices and students' scores on a measure of moral reasoning. When studying diversity courses, Mayhew, Seifert, and Pascarella (2012) observed moral and ethical development in students open to considering ethical dilemmas from multiple viewpoints compared to those that attempted to solve ethical issues with a consistent single-minded process that did not involve perspective-taking. Although some have begun to examine the relationship between communication pedagogy and ethical development, more studies should investigate such relationships between pedagogical interventions and students' ethical growth (Brandenberger \& Bowman, 2015; King \& Mayhew, 2002).

\section{Ethics Education in the Communication Classroom}

Communication scholars have been discussing the role of ethics education in communication classrooms for over three decades (e.g., Canary, 2007; Christians \& Lambeth, 1996; Groshek \& Conway, 2012; Jensen, 1985; Kienzler, 2001; McCaleb \& Dean, 1987; Sproule, 1987). Combined, they argue that fostering ethical development should be addressed in communication curricula. For example, Canary (2007) found that students in a conflict communication course with ethics education embedded in it experienced statistically significant increases in ethical development compared to students in a standalone communication ethics course. Her conclusions lend support to the notion expressed by others that ethical development can occur in courses not solely focused on communication ethics and may even be more effective in doing so (Groshek \& Conway, 2012; McCaleb \& Dean, 1987).

A number of communication scholars have proposed classroom activities that discuss ethics, sometimes explicitly (Darr, 2016; Palmer-Mehta, 2009; Smudde, 2011; Swenson-Lepper, 2012) and sometimes implicitly (Hanasono, 2013; Kahl, 2019). Scholars have also investigated how ethics may be taught through engaging pedagogical methods (e.g., target large and small group discussion, case study analyses, service learning; Canary, 2007; Canary et al., 2014). This study adds to the existing research on ethics and communication education by investigating the utility of an IEE-based academic intervention on students' ethical development. Ultimately, this study may provide instructors with a useful framework for fostering ethical development across communication curricula. As such, the following research questions were posed:

RQ1: How, if at all, does moral and ethical development occur during the first year of college after participating in an IEE-based academic intervention?

RQ2: How, if at all, does students' developmental phase and self-reported sex have an effect on the moral and ethical development that occurs during the first year of college?

\section{Theoretical Framework: Integrative Ethical Education}

The IEE model is a relationally based framework designed to foster ethical growth in educational settings. Originally developed by Narvaez (2006), it has since been refined and explained via five tenets (Boyd, 2010; Narvaez, 2006; Narvaez \& Bock, 2014). The five tenets are to:

... establish a caring relationship with each student ... establish a climate supportive of achievement and ethical character . . . teach ethical skills across the curriculum and extra-curriculum using a novice-to-expert pedagogy ... foster student self-authorship and self-regulation, 
[and] restore the village: asset-building communities and coordinated developmental systems. (Narvaez \& Bock, 2014, pp. 148-152)

Narvaez and Bock (2014) also explain what each of these tenets might look like in practice. To clarify, caring classroom climates and relationships emphasize demonstrating fairness and implementing democratic processes (Narvaez, 2011). Further, such climates provide students with opportunities to develop autonomy and to interact positively with peers (Narvaez \& Bock, 2014). Courses are structured using a novice-to-expert pedagogy where students get a good deal of hands-on support at the beginning of the semester and this support is gradually decreased as students gain knowledge and experience throughout the term. Moreover, instructors encourage students to verbally explain their thought processes while solving problems. Finally, instructors and students set high expectations to foster actively engaged members (Narvaez \& Bock, 2014).

\section{The Intervention}

The intervention examined in this study involved students participating in two academic courses: (a) an introductory leadership theory course, and (b) a leadership and ethics course. The introductory leadership theory course applied the tenants of the IEE model with an implicit focus on ethics; ethics was not a central topic discussed regularly in the course. The leadership and ethics course applied the tenants of the IEE model with an explicit focus on ethics; students were reading and applying a variety of theories of ethics to leadership practices throughout the semester. Additionally, the ethics and leadership course was designed as an applied oral communication course where students focused on how to communicate with others as leaders. Instructors for both courses were trained to implement the IEE model in their course and some instructors taught sections of both courses.

The IEE model was applied to the intervention in several ways. First, the curriculum and assignments for both courses were designed based on the program coordinators' interpretation of the IEE model. For example, in both courses, students' assignments built on one another in which students were provided more support at the beginning of the semester and less support toward the end of the semester (e.g., novice-to-expert pedagogy). Second, instructors attended pre-semester training sessions to discuss the educational environment called for by the IEE model. Third, in order to promote authentic and caring relationships, instructors had control over their online course portals and classroom interactions. As an example, one instructor included a personal introduction on the home page of their online course portal. Fourth, instructors completed example assignments for students as a model, such as presenting course content in the same format students would later present in. Finally, students were given multiple opportunities to work with their peers to discuss and apply course content to current events.

\section{Method}

\section{Participants}

Participants $(n=18)$ in this IRB approved study were first-year undergraduate students at a large, public, 4-year institution in the Southeast. They were recruited from an interdisciplinary university honors leadership program that applied the IEE model to various academic experiences in which students participated. To be eligible, participants had to be enrolled as first-year students during the Fall 2017 semester, be a member of their honors program's living-learning community, take leadership classes in the program, and be enrolled in an ethics and leadership course during the Spring 2018 semester. 
Participants' demographics represented those expected of traditional first-year students. See Table 1 for additional details.

\begin{tabular}{|c|c|c|}
\hline \multicolumn{3}{|l|}{$\begin{array}{l}\text { TABLE } 1 \\
\text { Participant Demographics }\end{array}$} \\
\hline Demographic & $n$ & $\%$ \\
\hline \multicolumn{3}{|l|}{ Age } \\
\hline 18 & 6 & $33 \%$ \\
\hline 19 & 12 & $67 \%$ \\
\hline \multicolumn{3}{|l|}{ Gender } \\
\hline Female & 9 & $50 \%$ \\
\hline Male & 9 & $50 \%$ \\
\hline \multicolumn{3}{|l|}{ Race/Ethnicity } \\
\hline Caucasian/White & 16 & $89 \%$ \\
\hline Asian/Pacific Islander & 2 & $11 \%$ \\
\hline \multicolumn{3}{|l|}{ Religion } \\
\hline Christian & 13 & $72 \%$ \\
\hline Not Religious & 3 & $17 \%$ \\
\hline Hindu & 2 & $11 \%$ \\
\hline \multicolumn{3}{|l|}{ Political View } \\
\hline Very Liberal & 2 & $11 \%$ \\
\hline Somewhat Liberal & 5 & $28 \%$ \\
\hline Neither Liberal nor Conservative & 2 & $11 \%$ \\
\hline Somewhat Conservative & 7 & $39 \%$ \\
\hline Very Conservative & 2 & $11 \%$ \\
\hline
\end{tabular}

\section{Measure}

The Defining Issues Test, Version 2 (DIT2), was used in this study as it is a valid and reliable measure of moral judgment (Bowman, 2011; Rest, Narvaez, Thoma, \& Bebeau, 1999). The DIT2 asked participants to read five scenarios that are considered ethical dilemmas and to rate statements about how they might respond to the dilemmas (Rest, Narvaez, Bebeau, \& Thomas, 1999). The DIT2 generated four scores: P score, N2 score, MN score, and personal interest score (Maeda et al., 2009).

The P score measures an individual's preference for postconventional moral thinking. Participants with higher P scores focus on duties derived from their own self-authored, critically examined moral and ethical purpose rather than from societal norms and laws (Maeda et al., 2009; Rest, Narvaez, Bebeau, \& Thomas, 1999). The N2 score adjusts the P score based on an individual's ability to differentiate between items that show postconventional thinking and those that show lower stages of moral and ethical thinking. The $\mathrm{MN}$ and personal interest scores both measure the degree to which participants emphasize lower schemas of moral judgment (Maeda et al., 2009). This study used P and N2 scores to learn about participants' progress toward postconventional thinking, the highest level of moral judgment. 
Participants' DIT2 responses were also used to determine their developmental phase and whether they could distinguish between the different moral schema. The responses of participants in the transition phase indicated that they did not clearly discriminate between the three moral schema, while those in the consolidation phase could distinguish between the schema and consistently responded in one schema (Bebeau \& Thoma, 2003).

\section{Procedure}

This exploratory study provides the foundation on which to build a larger, five-year longitudinal study. The current study used a pretest posttest design to examine participants' ethical development during the first year of college and their experiences in the intervention based on an interpretation of the IEE model (Narvaez, 2006; Narvaez \& Bock, 2014). Participants created a personal identification code so that their pre- and posttest responses could be matched without using identifying information.

\section{Pretest}

Pretest DIT2 measures were originally collected as program assessment data. Participants gave consent for their responses to be used in this study when completing the posttest. The DIT2 was administered via an online survey after participants had accepted admission to their institution and honors program. All participants completed the measure by the end of the second week of their first semester of classes.

\section{Posttest}

Participants completed the posttest measure during finals in their second semester of college after participating in the IEE-based intervention. Specifically, participants were asked to participate during the final exam session of their ethics and leadership course and were given time to complete the measure at the end of the exam period. Instructors provided participants with the link to an online survey to provide informed consent and complete the DIT2 measure. Participation in the study was voluntary, participants could withdraw at any time, and participation was not linked to a course grade.

\section{Data Analysis}

Participants' completed pre- and posttest DIT2 measures were scored by the Center for the Study of Ethical Development at the University of Alabama. The generated score report included a P score, N2 score, and developmental phase for each participant as well as other measures that were not used in this study. The higher a participant's $\mathrm{P}$ score, the more likely they were to make decisions using a postconventional schema. The N2 score adjusts the P score and indicates a participant's ability to discern between the postconventional and lower schemata (Maeda et al., 2009). After the scored DIT2 results were received, participants' personal identification codes were used to match their pre- and posttest scores. After some participants' submissions were purged by the Center for the Study of Ethical Development because they did not contain enough information to be scored, 18 participants' (35\% response rate) pre- and posttest scores were included in the data set used in this study's analysis.

The sample used in this study was drawn from a larger population of students enrolled in an interdisciplinary honors leadership program. As the sample was not randomly drawn, descriptive analysis was used to understand changes in participants' moral judgment during their first year of college. Specifically, percent changes were calculated to compare participants' average changes. Additionally, 
participants were grouped by developmental phase and self-reported sex to understand whether those individual characteristics influence changes in participants' moral judgment. Throughout the analysis, participants' $\mathrm{P}$ and $\mathrm{N} 2$ scores were used to understand their development toward the postconventional schema of moral judgment and their ability to discern between schemata.

\section{Results}

\section{Overall Change in Moral Development}

To understand participants' changes in moral judgment and development toward the postconventional schema, percent changes in participants' $\mathrm{P}$ and N2 scores from the pretest to the posttest were calculated.

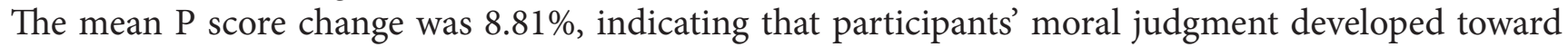
the postconventional schema during their first year of college. Further, the mean N2 score change was 9.30\%. This indicated that participants not only progressed toward the postconventional schema of moral judgment, but also improved their ability to differentiate between the postconventional and lower schemata of moral judgment (see Table 2).

\begin{tabular}{l|c|c|c|c|}
\hline \multicolumn{4}{|l|}{ TABLE 2 } \\
Participants' P and N2 Scores \\
\hline
\end{tabular}

\section{Differences Based on Developmental Phase}

Participants' DIT2 scores were compared based on their pretest developmental phase. Participants in the consolidation phase had an average change in P score of $-7.20 \%$ and an average change in N2 score of $-4.62 \%$. Thus, on average, these participants regressed. It is important to note that while participants in the consolidation phase saw decreases in both measures, their pretest-and in some cases posttestscores were higher than those of participants in the transition phase, who saw an average increase in $\mathrm{P}$ score of $36.23 \%$ and an average increase in $\mathrm{N} 2$ score of $35.08 \%$. Thus, participants in the transition phase had large average increases toward the postconventional schema of moral judgment and increased ability to discern between the postconventional schema and other schemata of moral judgment (see Table 3 ).

\section{Differences Based on Sex}

Participants were grouped by self-reported sex to further investigate changes in moral development. On average, increases in moral development occurred regardless of self-reported sex. All measures increased for both men and women in this study. Men in this sample had, on average, an $8.90 \%$ change in P score and a 12.34\% change in N2 score. Women in the sample had an average change in P score of $8.77 \%$ and an average change in $\mathrm{N} 2$ scores of $6.72 \%$. Although women had smaller percent change from the pretest to the posttest, it is important to note that, on average, the women in this sample had higher pre- and posttest P and N2 scores compared to men. Further, the women in this sample had a slightly 
larger positive change in P score (3.78) compared to men (3.56). However, because the mean pretest $\mathrm{P}$ score was higher for women, their percent change was smaller than that of men (see Table 4).

\begin{tabular}{|c|c|c|c|c|}
\hline \multicolumn{5}{|c|}{$\begin{array}{l}\text { TABLE } 3 \\
\text { Participants' P and N2 Scores Based on Moral Phase }\end{array}$} \\
\hline \multirow[b]{3}{*}{ Time Point } & \multicolumn{4}{|c|}{ Consolidation Phase $(n=10)$} \\
\hline & \multicolumn{2}{|c|}{ P Score } & \multicolumn{2}{|c|}{ N2 Score } \\
\hline & $M$ & SD & $M$ & SD \\
\hline Pretest & 47.20 & 13.67 & 49.79 & 9.51 \\
\hline \multirow[t]{3}{*}{ Posttest } & 43.80 & 14.34 & 47.49 & 10.70 \\
\hline & \multicolumn{4}{|c|}{ Transition Phase $(n=8)$} \\
\hline & \multicolumn{2}{|c|}{ P Score } & \multicolumn{2}{|c|}{ N2 Score } \\
\hline Time Point & $M$ & SD & $M$ & SD \\
\hline Pretest & 34.50 & 9.55 & 33.55 & 6.23 \\
\hline Posttest & 47.00 & 15.53 & 45.32 & 10.35 \\
\hline
\end{tabular}

\begin{tabular}{|c|c|c|c|c|}
\hline $\begin{array}{l}\text { TABLE } 4 \\
\text { Participants' P }\end{array}$ & Scores & ielf-Re & & \\
\hline & & & & \\
\hline & & & & \\
\hline Time Point & $M$ & SD & $M$ & SD \\
\hline Pretest & 40.00 & 9.59 & 38.89 & 9.24 \\
\hline Posttest & 43.56 & 15.71 & 43.69 & 10.88 \\
\hline & & & & \\
\hline & & & & \\
\hline Time Point & $M$ & SD & $M$ & SD \\
\hline Pretest & 43.11 & 16.80 & 46.25 & 12.89 \\
\hline Posttest & 46.89 & 13.97 & 49.36 & 9.41 \\
\hline
\end{tabular}

\section{Discussion}

The purpose of this exploratory study was to understand how students' participation in an IEE-based academic experience affected their ethical development during the first year of college. To answer the first research question, average changes in moral judgment were calculated for the entire sample, revealing that participants' level of ethical development increased (i.e., their P and N2 score changes were positive). To answer the second research question, average changes in moral judgment were calculated for participants grouped by developmental phase and self-reported sex. The results indicated that participants in the transition phase experienced, on average, positive changes in moral judgment, while participants in the consolidation phase experienced, on average, negative changes in moral 
judgment based on changes in both P and N2 scores. Comparison of participants based on self-reported sex revealed that both men and women had average positive changes in their $\mathrm{P}$ and $\mathrm{N} 2$ scores from the pretest to the posttest. This section of the paper discusses these findings in relation to the literature on college students' moral and ethical development in academic settings.

\section{Overall Changes in Ethical Development}

Scholars have consistently found that moral and ethical development occurs during the first year of college (King \& Mayhew, 2002; Mayhew, Rockenbach, et al., 2016; Pascarella \& Terenzini, 1991, 2005). This study's participants showed, on average, positive growth toward the postconventional schema of moral judgment (based on the positive changes in P scores) and increased ability to differentiate between the postconventional schema and lower schema (based on the positive changes in N2 scores). Participants in the current study experienced, on average, larger increases in moral and ethical development than those represented by normed DIT2 data from 2005 to 2009 (Dong, n.d.). The normed data showed that the average change in the P score from freshman to sophomore year was 1.12 and the average change in the $\mathrm{N} 2$ score was 1.18 (Dong, n.d.). In the current study, participants showed an average $\mathrm{P}$ score change of 3.67 and an average N2 score change of 3.96 during their first year of college, during which they participated in an IEE-based academic intervention. Therefore, this study's participants showed more than double the positive growth compared to the participants represented by the normed data. While the overall positive changes observed in this study are not generalizable to the population at large, the comparisons to the normed data and discussion of the findings in relation to the literature (which are presented below) suggest that the findings have practical significance for instructors' pedagogical practice.

\section{Individual Characteristics and Ethical Development}

Scholars have found that a host of individual characteristics relevant to this study's population, including first-year student status (Pascarella, Blaich, et al., 2011), prior academic achievement (Corcoran \& O'Flaherty, 2016), self-reported sex (King \& Mayhew, 2004), and developmental phase (Mayhew, Seifert, \& Pascarella, 2012), are related to increased levels of moral and ethical development. A longitudinal study of moral development over four years revealed that while participants experienced moral gains from the first to fourth year of college, the majority of these gains occurred during the first year (Mayhew, Rockenbach, et al., 2016; Pascarella, Blaich, et al., 2011). Therefore, it was expected that the participants in this study would exhibit increased moral development during the first year of college. As high-achieving honors students, the participants in this study were expected to have higher levels of moral and ethical development than their non-honors program peers as scholars have found that prior academic achievement is connected to increased moral and ethical development (Corcoran \& O'Flaherty, 2016). However, it is important to note that researchers have found that all students have the ability to develop ethically during college, regardless of their prior academic achievement (Maeda et al., 2009). Although it was expected that the participants' moral and ethical development would increase based on the literature, the changes observed in this study exceeded expectations when compared to normed DIT2 data (Dong, n.d.).

Analysis of changes in moral judgment based on participants' self-reported sex showed that female participants had slightly more positive change in $\mathrm{P}$ scores compared to their male peers, and male participants were found to have slightly more positive change in N2 scores compared to their female 
peers. These findings align with the results of previous investigations of the connection between moral and ethical development and sex. In reviews of over 50 studies-including multiple studies that used meta-analytic methods (Thomas, 1986; Walker, 1984)-scholars observed that a large majority found that either women scored higher than men or there was no significant difference in moral and ethical development between men and women (King \& Mayhew, 2004; Mayhew, Seifert, Pascarella et al., 2012). Although small differences were observed in this study, based on the literature, it is unlikely that selfreported sex influenced the overall moral and ethical development of participants.

This study also investigated how participants' pretest developmental phase influenced their moral and ethical development while participating in the IEE-based intervention. Participants who were in the transition phase experienced, on average, greater changes in their P and N2 scores compared to their peers in the consolidation phase. This suggests that the IEE-based intervention-which focused on helping students develop skills like empathy and perspective-taking - was more effective for participants in the transition phase. This finding is consistent with the limited body of research investigating the effect of students' developmental phase on their moral and ethical development (Mayhew, Seifert, \& Pascarella, 2012). While studying diversity-related courses, Mayhew, Seifert, and Pascarella (2012) found that participants in the transition phase experienced an increased positive change in a measure of moral judgment compared to participants in the consolidation phase. They suggested that students in the consolidation phase may not have been able to engage in perspective-taking, which is an important aspect of ethical development and decision-making (Mayhew, Seifert, \& Pascarella, 2012). The results of the current study support Mayhew, Seifert, and Pascarella's (2012) findings and conclusion. It is also important to note that participants in the consolidation phase exhibited decreased DIT2 scores after participating in the IEE-based intervention.

Participants in the consolidation phase had an average change in P score of $-3.40(-7.20 \%)$ and N2 score of $-2.39(-4.62 \%)$, indicating that their moral and ethical development regressed while participating in the IEE-based intervention. Researchers have previously found that moral and ethical development occurs when students are faced with cognitive dissonance, which is often experienced after encountering difference (Mayhew \& Engberg, 2010; Mayhew, Seifert, \& Pascarella, 2010; Mayhew, Seifert, \& Pascarella, 2012; Spear \& Miller, 2012). It is likely that the level of ethical development of participants in the consolidation phase regressed because they were uncomfortable with some of the IEE-based intervention's diversity-related content, did not have the necessary perspective-taking skills to engage with the content, and were not supported in a way that promotes moral growth (Mayhew \& Engberg, 2010). Kohlberg $(1975,1976)$ and Perry's $(1970)$ theories of moral, ethical, and intellectual development both support the conclusion that developmental regression can occur when college students are challenged without the necessary support (Sanford, 1966).

Further, there could be a link between the processes of ethical and intercultural development, as scholars studying college students' reactions to diverse populations found that when students felt uncomfortable or their perspectives were challenged, their intercultural development regressed (King, Baxter Magolda, \& Massé, 2011). These findings support Mayhew and Engberg’s (2010) assertion that when discussing diversity-related ideas and engaging with differences, the academic environment needs to be appropriately structured with the necessary level of support to ensure that academic programs and courses help all students experience ethical growth. In addition to individual characteristics, the environmental factors of the intervention contributed to participants' ethical development. 


\section{Environmental Factors and Ethical Development}

The IEE-based intervention incorporated a number of experiences and activities that scholars have connected to students' moral and ethical development (Mayhew, Rockenbach, et al., 2016). While participating in the IEE-based intervention, students experienced a course that included explicit moral content (Aalberts et al., 2012; Mayhew \& King, 2008); a curriculum that promoted the development of skills like empathy, perspective-taking, and critical thinking; multiple frameworks for deciding what is ethical and ways to apply those frameworks to relevant case studies (Mayhew, Seifert, \& Pascarella, 2010; Walling, 2015); and a pedagogical approach that promoted peer-to-peer and student-faculty interactions inside and outside the classroom (Mayhew, Seifert, \& Pascarella, 2010; Parker, 2017). The use of activities and pedagogical strategies previously connected to increases in moral and ethical development was intended to affect participants' development beyond what would be expected of a typical first-year college student.

Regarding the larger increases in students' moral and ethical development compared to the normed data (Dong, n.d.), students' gains in this study can, in part, be attributed to the IEE-based intervention, as it intentionally employed practices previously connected to moral and ethical development. Additionally, while it was expected that participants would experience moral and ethical growth based on their individual characteristics, the gains observed in this study are beyond what is expected, indicating that the academic environment created by the IEE-based intervention positively affected participants' moral and ethical development. The findings of this study have practical significance for communication education pedagogy and future research.

\section{Implications}

Although the ethical development observed during this study cannot be attributed solely to the IEEbased academic intervention or generalized to the population at large, the findings do indicate that the intervention was successful for this study's participants. Thus, it is beneficial to use the IEE model as a framework to develop communication courses that promote ethical development. Communication scholars (Groshek \& Conway, 2012; McCaleb \& Dean, 1987) have argued that ethics education should not only be present in communication ethics courses but weaved throughout communication curricula. As the IEE model proposes an educational environment that promotes ethical development, it can be used as a framework not only for courses that directly focus on ethics but for any communication course (Narvaez \& Bock, 2014).

Researchers have found that class discussions and case studies-both pedagogical strategies that can be applied in a variety of communication courses-are pedagogical approaches that promote ethical development (Canary, 2007; Canary et al., 2014). The holistic intervention in this study used peer-topeer interactions, small group discussions, class discussion, and case studies as pedagogical strategies, supported by the IEE model, that could be applied to promote students' ethical development in communication courses. For example, when teaching a course on persuasive communication, instructors could have students in small groups analyze persuasive messages to identify how persuasive theories were applied and if the messages are appropriate for the context they were shared in.

When implementing the pedagogical strategies discussed above and applying the IEE model, instructors should use novice-to-expert pedagogy. At the beginning of the semester, instructors should provide a high level of support to students and model how students can successfully complete the assignments. As 
the semester progresses, instructors should become more hands-off and allow students to be responsible for regulating their behavior and engaging with assignments with less support.

When teaching the foundational communication course that focuses on public speaking, instructors could begin the semester by providing significant feedback for students on how they could improve their presentational speaking. Additionally, instructors could give their own presentation-that fits with the first speaking assignment students complete-to provide an example for students. As the semester progresses and students become more comfortable presenting in front of the class, instructors could provide less feedback on students' delivery and focus on more advance concepts (e.g., arguments presented in a persuasive presentation). Instructors that teach more advanced students (e.g., junior or senior undergraduates, graduate students) could also use this pedagogy, but they may not provide as much support at the beginning of the semester as they would when teaching first-year college students. The IEE model provides a strong theoretical foundation that communication instructors could use when implementing pedagogical practices that scholars have found to promote student's ethical development in communication courses.

The IEE model calls for the use of "coordinated developmental systems" (Narvaez \& Bock, 2014, p. 152), encouraging the use of partnerships across campus and with members of the community to provide students with learning opportunities that tie their academic work to practical experiences outside the classroom and their practical experiences to academic work in the classroom. This suggestion is in line with those of communication scholars that argued there should be a practical focus when incorporating ethics education into a curriculum (Canary, 2007; Canary et al., 2014).

Service learning could be one approach to creating these opportunities in communication courses. For example, if students are learning about organizational communication, they could complete service opportunities with an organization. Instructors could then debrief these experiences with students in class to help them connect theory to their practical experience. Strategies like these could be used by communication instructors to create the developmental systems called for by Narvaez and Bock (2014) to promote ethical development while giving students the opportunity to practice the communication skills they are learning in a practical setting. Overall, the participants in this study experienced positive ethical development, but the developmental regression of participants in the consolidation phase warrants specific attention when implementing the IEE model in communication courses.

Sproule (1987) and Swenson-Lepper et al. (2015) noted that instructors must consider whose ethics are present in the classroom and acknowledge that the application of ethics content involves engaging with others, including those who are different from oneself. They drew attention to the fact that instructors must consider whose voice has a place in the classroom and the connection between ethics education and the topics of diversity and inclusion. As scholars have called for the inclusion of ethics content across communication curricula, the same has been suggested for diversity-related content (Ashby-King \& Hanasono, 2019; Wahl et al., 2016). Darr (2016) and Swenson-Lepper (2012) both proposed in-class activities that connected ethics and diversity content in the communication classroom. Activities like these could provide instructors the opportunity to nudge students toward the cognitive dissonance that promoted ethical development (Mayhew \& Engberg, 2010). However, it is important that the necessary support mechanisms are in place to ensure that students' ethical development does not regress.

Ashby-King and Hanasono (2019) posited that when teaching diversity-related content in the communication discipline, which could include activities similar to those proposed by Darr (2016) and 
Swenson-Lepper (2012), instructors should discuss power, privilege, and structural inequity. Although these are important discussions, they may push some students toward a level of discomfort that causes their ethical development to regress. Thus, it is important to provide students appropriate support. Although Mayhew and Engberg (2010) asserted this, they did not explicitly outline what that support should look like. We argue that one approach to providing this support is giving students the opportunity to engage in reflective writing assignments about the topics discussed. This could allow instructors to understand how students are reacting to course content in order to provide support when necessary. This is an area upon which communication instructors and scholars can build by performing applied research to ensure that students have the necessary experiences to achieve ethics and diversity-based learning outcomes (NCA, 2015).

\section{Limitations and Future Research}

When considered in relation to the results of this study, several limitations point to avenues for future research. First, this exploratory study had a small sample size and did not include an experimental design. This limited the study's explanatory power and the generalizability of the results. To overcome these limitations in future research, scholars could conduct similar studies using a quasi-experimental design and a control group. For example, researchers could investigate ethical development in a multisection course. Keeping the course content the same, instructors in half the sections could employ the IEE model while the remaining instructors teach the course as it has traditionally been taught. By measuring students' moral and ethical judgment at the beginning and end of the semester, scholars would have the opportunity to compare the changes in students' scores between groups to more clearly understand if the IEE model influenced students' ethical development.

Second, this study did not use any measures to investigate which specific aspects of the intervention or instructor behaviors affected students' ethical development. Instructional communication scholars have developed several measures that can be used to understand how students experience and understand their interactions with their instructors and peers. Scholars could advance this line of research by using measures related to instructors' behaviors that are called for by the IEE model, such as the perceived caring subscale of McCroskey \& Teven's (1999) instructor credibility scale, to investigate which aspects of and how the IEE model promotes students' ethical development.

Third, to further enhance educational practice, scholars need to investigate the developmental regression experienced by this study's participants in the consolidation phase. While scholars have suggested that regression will not occur if students are given the necessary support (Mayhew \& Engberg, 2010), what that support should look like in practice has not been outlined. Communication and instruction scholars have the opportunity to extend this research by identifying pedagogical practices and instructor and student communication behaviors that limit the developmental regression that occurs when students are uncomfortable with the content of communication courses.

Finally, this study did not investigate the application of the IEE model in a communication course; therefore, while the study's findings can still inform communication instructors' practice, scholars have the opportunity to extend this work by investigating applications of the IEE model to a communication curriculum. As proposed by Canary (2007), this study investigated first-year college students. When investigating IEE-based communication courses, researchers could use a longitudinal design to track students' development throughout their collegiate experience to understand how students' development occurs over time. 


\section{Conclusion}

The communication discipline has a role to play in college students' ethical development as doing so prepares graduates to actively engage in democratic society (Colby et al., 2003; NCA, 2015). Conclusions drawn from this exploratory study suggest that an IEE-based academic intervention embedded in the first-year experience may achieve positive ethical communication learning outcomes. Further research is warranted to identify additional evidence-based practices that instructors can employ to promote college students' ethical development, to act on their self-authored ethical beliefs (Juujarvi et al., 2010).

\section{References}

Aalberts, J., Koster, E., \& Boschhuizen, R. (2012). From prejudice to reasonable judgments: Integrating (moral) value discussions in university courses. Journal of Moral Education, 41(4), 437-455. https:// doi.org/10.1080/03057240.2012.677600

American Council on Education. (1937). The student personnel point of view: American Council on Education Studies (Series I, Vol. I, No. 3). American Council on Education.

Ashby-King, D. T., \& Hanasono, L. K. (2019). Diverging discourses: Examining how college students majoring in communication define diversity. Qualitative Research Reports in Communication, 20(1), 9-18. https://doi.org/10.1080/17459435.2019.1572645

Association of American Colleges and Universities. (2005). Liberal education outcomes: A preliminary report on student achievement. Association of American Colleges and Universities.

Association of American Colleges and Universities. (2007). College learning for the global century: Executive summary with findings from employer survey. Association of American Colleges and Universities.

Auger, G. A., \& Gee, C. (2016). Developing moral maturity: An evaluation of the media ethics course using the DIT-2. Journalism \& Mass Communication Educator, 71(2), 146-162. https://doi. org/10.1177/1077695815584460

Bebeau, M. J., \& Thoma, S. J. (2003). Guide for DIT-2, A guide for using the defining issues test, version 2 ("DIT-2") and the scoring service of the center for the study of ethical development. Center for the Study of Ethical Development.

Bowman, N. A. (2011). Examining systematic error in predictors of college student self-reported gains. New Direction for Institutional Research, 150, 7-19. https://doi.org/10.1002/ir.386

Boyd, K. D. (2010). The nature of the student-institution relationship and behavioral indicators of personal and social responsibility: An exploration of the association between relational quality outcomes, alcohol use, and academic honesty (Unpublished doctoral dissertation). University of Georgia.

Brandenberger, J. W., \& Bowman, N. A. (2015). Prosocial growth during college: Results of a national study. Journal of Moral Education, 44(3), 328-345. https://doi.org/10.1080/03057240.2015.1048792

Canary, H. E. (2007). Teaching ethics in communication courses: An investigation of instructional methods, course foci, and student outcomes. Communication Education, 56(2), 193-208. https://doi. org/10.1080/03634520601113660

Canary, H. E., Taylor, J. L., Herkert, J. R., Ellison, K., Wetmore, J. M., \& Tarin, C. A. (2014). Engaging students in integrated ethics education: A communication in the disciplines study of pedagogy and students' roles in society. Communication Education, 63(2), 83-104. https://doi.org/10.1080/036345 23.2014.888457

Christians, C. G., \& Lambeth, E. B. (1996). The status of ethics instruction in communication departments. Communication Education, 45, 236-243. https://doi.org/10.1080/03634529609379052

Colby, A., Ehrlich, T., Beaumont, E., \& Stephens, J. (2003). Educating citizens: Preparing America's undergraduates for lives of moral and civic responsibility. Jossey-Bass. 
Corcoran, R. P., \& O'Flaherty, J. (2016). Examining the impact of prior academic achievement on moral reasoning development among college students: A growth curve analysis. Journal of Moral Education, 45(4), 433-448. https://doi.org/10.1080/03057240.2016.1230051

Darr, C. R. (2016). Debating diversity: Ethics and controversial public issues. Communication Teacher, 30(3), 147-152. https://doi.org/10.1080/17404622.2016.1192660

Dong, Y. (n.d.). Norms for DIT2: From 2005-2009. Center for the Study of Ethical Development. http:// ethicaldevelopment.ua.edu/uploads/8/4/9/8/84986096/norms-for-dit2_05-09_.pdf

Groshek, J., \& Conway, M. (2012). The effectiveness of the pervasive method in ethics pedagogy: A longitudinal study of journalism and mass communications students. Journalism, 14(3), 330-347. https://doi.org/10.1177/1464884912454503

Hanasono, L. K. (2013). Virtual voices with real-life consequences: Teaching students about cyber-vetting. Communication Teacher, 27(4), 191-197. https://doi.org/10.1080/17404622.2013.798010

Hurtado, S., Mayhew, M. J., \& Engberg, M. E. (2012). Diversity courses and students' moral reasoning: A model of predispositions and change. Journal of Moral Education, 41(2), 201-224. https://doi.org/ 10.1080/03057240.2012.670931

Jensen, J. V. (1985). Teaching ethics in speech communication. Communication Education, 34, 324-330. https://doi.org/10.1080/03634528509378624

Juujarvi, S., Myyry, L., \& Pesso, K. (2010). Does care reasoning make a difference? Relations between care, justice and dispositional empathy. Journal of Moral Education, 39(4), 469-489. https://doi.org/ $10.1080 / 03057240.2010 .521381$

Kahl, D. J., Jr. (2019). Challenging neoliberal justification for labor exploitation through the application of critical communication pedagogy. Communication Teacher, 33(4), 286-291. https://doi.org/10.10 80/17404622.2019.1575437

Kienzler, D. (2001). Ethics, critical thinking, and professional communication pedagogy. Teaching Communication Quarterly, 10(3), 319-339. https://doi.org/10.1207/s15427625tcq1003_5

King, P. M., Baxter Magolda, M. B., \& Massé, J. C. (2011). Maximizing learning from engaging across difference: The role of anxiety and meaning making. Equity \& Excellence in Education, 44(4), 468487. https://doi.org/10.1080/10665684.2011.608600

King, P. M., \& Mayhew, M. J. (2002). Moral judgment development in higher education: Insights from the defining issues test. Journal of Moral Education, 31(3), 247-270. https://doi. org/10.1080/0305724022000008106

King, P. M., \& Mayhew, M. J. (2004). Theory and research on the development of moral reasoning among college students. In J. C. Smart (Ed.), Higher education: Handbook of theory and research (Vol. 19, pp. 375-440). Kluwer Academic Publishers. https://doi.org/10.1007/1-4020-2456-8_9

Kohlberg, L. (1975). The cognitive-developmental approach to moral education. The Phi Delta Kappan, 56(10), 670-677. http://www.jstor.org/stable/20298084

Kohlberg, L. (1976). Moral stages and moralization: The cognitive-developmental approach. In T. Lickona (Ed.), Moral development and behavior (pp. 31-53). Holt, Rinehart \& Winston.

Lies, J. M., Bock, T., Brandenberger, J., \& Trozzolo, T. A. (2012). The effects of off-campus service learning on the moral reasoning of college students. Journal of Moral Development, 41(2), 189-199. https:// doi.org/10.1080/03057240.2012.669925

Maeda, Y., Thoma, S. J., \& Bebeau, M. J. (2009). Understanding the relationship between moral judgment development and individual characteristic: The role of educational contexts. Journal of Educational Psychology, 101(1), 233-247. https://doi.org/10.1037/a0013381

Mayhew, M. J., \& Engberg, M. E. (2010). Diversity and moral reasoning: How negative diverse peer interactions affect the development of moral reasoning in undergraduate students. Journal of Higher Education, 81(4), 459-488. https://doi.org/10.1080/00221546.2010.11779061 
Mayhew, M. J., \& King, P. (2008). How curricular content and pedagogical strategies affect moral reasoning development in college students. Journal of Moral Education, 37(1), 17-40. https://doi. org/10.1080/03057240701803668

Mayhew, M. J., Rockenbach, A. N., Bowman, N. A., Seifert, T. A., Wolniak, G. C., Pascarella, E. T., \& Terenzini, P. T. (2016). How college affects students: 21st century evidence that higher education works (Vol. 3). Jossey-Bass.

Mayhew, M. J., Seifert, T. A., \& Pascarella, E. T. (2010). A multi-institutional assessment of moral reasoning development among first-year students. The Review of Higher Education, 33(3), 357-390. https:// doi.org/10.1353/rhe.0.0153

Mayhew, M. J., Seifert, T. A., \& Pascarella, E. T. (2012). How the first year of college influences moral reasoning development for students in moral consolidation and moral transition. Journal of College Student Development, 53(1), 19-40. https://doi.org/10.1353/csd.2012.0004

Mayhew, M. J., Seifert, T. A., Pascarella, E. T., Nelson Laird, T. F., \& Blaich, C. F. (2012). Going deep into mechanism for moral reasoning growth: How deep learning approaches affect moral reasoning development for first-year students. Research in Higher Education, 53(1), 26-46. https://doi. org/10.1007/s11162-011-9226-3

McCaleb, J. L., \& Dean, K. W. (1987). Ethics and communication education: Empowering teachers. Communication Education, 36, 410-416. https://doi.org/10.1080/03634528709378696

McCroskey, J. C., \& Teven, J. J. (1999). Goodwill: A reexamination of the construct and its measurement. Communications Monographs, 66(1), 90-103. https://doi.org/10.1080/03637759909376464

Narvaez, D. (2006). Integrative ethical education. In M. Killen \& J. Smetana (Eds.), Handbook of moral development (pp. 703-733). Erlbaum.

Narvaez, D. (2011). Building a sustaining classroom climate for purposeful ethical citizenship. In T. Lovat, R. Toomey, \& N. Clement (Eds.). International research handbook on values education and student wellbeing (pp. 659-674). Springer. https://doi.org/10.1007/978-90-481-8675-4_38

Narvaez, D., \& Bock, T. (2014). Developing ethical expertise and moral personalities. In L. Nucci, D. Narvaez, \& T. Krettenauer (Eds.), Handbook of moral and character education (pp. 140-158). Routledge.

National Communication Association (NCA). (2015). What should a graduate with a communication degree know, understand and be able to do? https://www.natcom.org/sites/default/files/publications/ LOC_1_What_Should_a_Graduate_with_a_Communication_Degree.pdf

O'Neill, N. (2011). Educating for personal and social responsibility: Levers for building collective institutional commitment. Journal of College \& Character, 12(2), 1-6. https://doi.org/10.2202/19401639.1792

Palmer-Mehta, V. (2009). Motivational appeals and ethics. Communication Teacher, 23(1), 41-47. https:// doi.org/10.1080/17404620802592932

Parker, E. (2017). Do non-classroom interactions with faculty affect moral development among college students? College Student Affairs Journal, 35(1), 3-12. https://doi.org/10.1353/csj.2017.0001

Parker, E. T., Barnhardt, C. L., Pascarella, E. T., \& McCowin, J. A. (2016). The impact of diversity courses on college students' moral development. Journal of College Student Development, 57(4), 395-410. https://doi.org/10.1353/csd.2016.0050

Pascarella, E. T., Blaich, C., Martin, G. L., \& Hanson, J. M. (2011). How robust are the findings of "Academically Adrift"? Change: The Magazine of Higher Learning, 43(3), 20-24. https://doi.org/10.1080/0 0091383.2011 .568898 
Pascarella, E. T., \& Terenzini, P. T. (1991). How college affects students: Findings and insights from twenty years of research. Jossey-Bass.

Pascarella, E. T., \& Terenzini, P. T. (2005). How college affects students: A third decade of research. JosseyBass.

Perry, W. G., Jr. (1970). Forms of intellectual and ethical development in the college years: A scheme. Holt, Rinehart, \& Winston.

Rest, J., Narvaez, D., Bebeau, M. J., \& Thomas, S. J. (1999). Postconventional moral thinking: A neoKohlbergina approach. Lawrence Erlbaum. https://doi.org/10.4324/9781410603913

Rest, J. R., Narvaez, D., Thoma, S. J., \& Bebeau, M. J. (1999). DIT2: Devising and testing a revised instrument of moral judgment. Journal of Educational Psychology, 91(4), 644-659. https://doi. org/10.1037/0022-0663.91.4.644

Sanford, N. (1966). Self and society: Social change and individual development. Atherton.

Smudde, P. M. (2011). Focus on ethics and public relations practice in a university classroom. Communication Teacher, 25(3), 154-158. https://doi.org/10.1080/17404622.2011.579907

Spear, J. A., \& Miller, A. N. (2012). The effects of instructor fear appeals and moral appeals on cheatingrelated attitudes and behavior of university students. Ethics and Behavior, 22(3), 196-207. https://doi. org/10.1080/10508422.2012.659603

Sproule, J. M. (1987). Whose ethics in the classroom? An historical survey. Communication Education, 36, 317-326. https://doi.org/10.1080/03634528709378683

Swenson-Lepper, T. (2012). Teaching communication ethics and diversity: Using technology and community engagement to enhance learning. Communication Teacher, 26(2), 228-235. https://doi.org/ 10.1080/17404622.2012.700719

Swenson-Lepper, T., Leavitt, M. A., Hoffer, M., Charron, L. N., Ballard, R. L., Bell, L. M., Holba, A. M., Jovanovic, S., \& Tompkins, P. S. (2015). Communication ethics in the communication curriculum: United States, Canada, Puerto Rico. Communication Education, 64(4), 472-490. https://doi.org/10.1 080/03634523.2015.1041996

Thomas, S. J. (1986). Estimating gender differences in the comprehension and preference of moral issues. Developmental Review, 6, 165-180. https://doi.org/10.1016/0273-2297(86)90010-9

Wahl, S. T., Williams, K. M., Berkos, K. M., \& Disbrow, L. M. (2016). “Diversity matters" continued: Student learning outcomes in communication. Communication Education, 65(4), 488-490. https:// doi.org/10.1080/03634523.2016.1202999

Walker, L. J. (1984). Sex differences in the development of moral reasoning: A critical review. Child Development, 55, 677-691. https://doi.org/10.2307/1130121

Walling, O. (2015). Beyond ethical frameworks: Using moral experimentation in the engineering ethics classroom. Science and Engineering Ethics, 21, 1637-1656. https://doi.org/10.1007/s11948-014-9614-0 